$2^{\text {nd }}$ International Conference Art, Illustration and Visual Culture in Infant and Primary Education

\title{
Construyendo la memoria visual a través de la fotografía
}

Noemi Peña Sánchez noemipes@yahoo.es University of Valladolid, España

Reference

Sánchez, Noemi Peña; (2012) "Construyendo la memoria visual a través de la fotografía", p. 108-112 . In: Barbosa, Helena; Quental, Joana [Eds]. Proceedings of the 2nd International Conference of Art, Illustration and Visual Culture in Infant and Primary Education. São Paulo: Blucher, 2015. ISSN 2318-695X, ISBN: 978-989-98185-0-7 DOI 10.5151/edupro-aivcipe-22

El entorno que nos rodea es un gran contenedor de mensajes visuales de los que estamos más que acostumbrados a consumir. Sin embargo, ese mundo visual también despierta interés y debe enseñarse a las personas ciegas. La educación artística debe proporcionarles recursos y estrategias para saber mirar, pensar y crear. Esta experiencia investiga sobre la percepción del invidente a través de la fotografía y nos permite descubrir aspectos que enriquecerán nuestra propia forma de mirar. Comprender la capacidad de percepción de las personas ciegas y de cómo construyen imágenes a través de la fotografía son parte de los objetivos que nos planteamos.

Esta investigación se ha desarrollado en una asignatura de educación artística con una estudiante ciega de la Facultad de Educación de la Universidad de Valladolid.Este proyecto nos ha permitido adentrarnos en el imaginario visual del invidente y concienciarnos sobre el papel activo que debe tomar la educación artística en la enseñanza de un entorno visual accesible también a personas invidentes. percepción invidente, fotografía, creación artística, memoria e imaginación

\section{Abstract}

We are surrounded by a lot of visual messages, which come to us from the pictures we constantly see. However, this visual world my raise interest to blind people and should be taught to them. Art education should provide resources and strategies to teach how to look, how to think and how to create. By this project, we try to find out how the blind perception works through photography and this will allow us to discover many other aspects that enrich our own way of looking.

So, there are two main objectives we set in our research. First, to understand how blind people perceive and second to comprehend the way images are constructed for blind people. This project has been developed with a blind student in an art education subject at the University of Valladolid. Furthermore, it has helped us to get inside the visual imagery of a blind person and raise awareness of the active role that art education must take when we are teaching to blind people.

blind perception, photography, art creation, memory and imagination

\section{Introducción}

Esta experiencia nace del interés que siempre ha despertado en mí la idea de mirar a través del visor de la cámara fotográfica y de cómo las fotografías son, al fin y al cabo, modos de observar. En esta inquietud, surge la necesidad de descubrir otra mirada, la de aquellas personas que no pueden ver pero que poseen otros modos de percibir como si de una mirada invisible se tratase. 
$2^{\text {nd }}$ International Conference Art, Illustration and Visual Culture in Infant and Primary Education
${ }^{\circ}$ Congresso Internacional

de Arte, llustracão e Cultura Visual

na Educação Infantil e Primária

El cuerpo y los sentidos nos permiten conectar con el mundo y sentir que formamos parte de nuestro entorno. La vista junto al resto de sentidos son los canales sensoriales que captan selectivamente aspectos de la realidad que nos interesan. La inteligencia procesa la información percibida a través del pensamiento, generando nuestras propias ideas las cuales nos definen y distinguen como individuos.

La percepción es el inicio del camino hacia la construcción del conocimiento. Los sentidos conectan el mundo interno con el externo. De este modo la incorporación de estas percepciones es el eslabón inicial para la construcción de imágenes mentales.(Gratacós, 2006: 53)

De modo que la percepción nos conduce a la creación poniendo en funcionamiento la imaginación y la memoria. La imaginación es como un interruptor que encendemos y que junto a toda esa información percibida y almacenada en la memoria genera nuevas ideas que se visualizan interiormente como representaciones mentales. Según Menchén (1998, pp.30) podemos encontrarnos con dos tipos: las imágenes reproductivas que evocan formas conocidas y las imágenes creadoras que generan representaciones originales fruto de la asociación de imágenes almacenadas en nuestra memoria.

La fotografía nos sirve como referencia para construir mentalmente estas imágenes y trabajar de este modo con el imaginario visual del invidente. La creación de imágenes originales es la fase final de todo un proceso creativo que demuestra cómo las personas ciegas también son capaces de generar imágenes a partir de fotografías que aparentemente no pueden mirar.

1 Planificación y objetivos.

Esta experiencia se llevó a cabo con una estudiante ciega en la asignatura obligatoria Creación artística, cultura visual y musical de $3^{\circ}$ curso de Grado de Educación Primaria en la Facultad de Educación de la Universidad de Valladolid. Dicha asignatura se imparte por profesorado especialista en las áreas de plástica y música y completaría la formación artística iniciada en cursos previos. Su finalidad es dotar al estudiante de estrategias y recursos en el manejo de los lenguajes visual y musical para que sean capaces de crear e integrar ambas disciplinas en su futura práctica docente. A continuación, se definen los objetivos correspondientes al área de plástica:

- Despertar el interés por lo visual y comprender que ese mundo de imágenes sigue formando parte del entorno visual de la persona invidente.

- Reconocer modos de apropiarnos de lo visual desde la propia experiencia y el contacto sensorial con el entorno próximo.

- Aprender a leer imágenes desde la mirada invidente.

- Reconstruir la memoria visual del invidente a través de la experimentación y autoidentificación con la obra artística.

- Aportar significación a la imagen fotográfica y ser capaces de crear y valorar nuestras propias fotografías.

Las sesiones de trabajo se han planificado durante dos días a la semana en el segundo semestre siguiendo el calendario oficial. Partiendo de la idea de desarrollar una propuesta en el que los contenidos teóricos y prácticos se fueran trabajando conjuntamente, le propusimos la creación de un scrapbook. La idea de crear un álbum de recortes a modo de diario de artista nos permitía incluir variedad de creaciones desde dibujos, collages, fotografías, documentos en braille, así como cualquier otro material que se considerara relevante añadir.

\section{Desarrollo de la experiencia.}

Comenzamos por hacer un recorrido por las imágenes que forman parte del entorno visual y concienciarnos sobre cómo son percibidas por las personas ciegas. Los mensajes visuales se presentan en una variedad de soportes y se distinguen de otros lenguajes por su eficacia comunicativa y expresiva. En nuestro caso, utilizamos la fotografía como fuente principal de imágenes y especialmente aquellas imágenes que formaban parte del ábum personal de fotografías de la estudiante. 
2nd International Conference Art, lllustration and Visual Culture in Infant and Primary Education
Traer las fotografías al aula no sólo significaba entrar en su mundo visual sino dotar de importancia a ese lenguaje aparentemente prohibido a las personas ciegas. Se realizaron diferentes lecturas para comprender y aportar significados a la imagen antes de dar el paso de la creación. Según Ewald (2001,p.17) al leer imágenes no sólo aprendemos a mirar más conscientemente lo que nos rodea, sino que comprendemos como se combinan sus elementos para comunicar ideas y evocar sensaciones. Aprender a mirar imágenes potencia la observación, al tiempo que nos permite reflexionar sobre cómo los elementos que integran la fotografía son capaces de comunicar primero visual y después emocionalmente.

La creación artística que nos interesa es la que se construye desde las ideas, la que es capaz de generar imágenes desde el imaginario de cada individuo al margen de que éste sea ciego. En este sentido, parece necesario nombrar al fotógrafo ciego Evgen Bavcar, creador de imágenes mentales a través de la fotografía y a quien podríamos denominar más acertadamente iconógrafo. Sus fotografías son huellas de las imágenes mentales construidas en su memoria fruto de un deseo de representación interior de imágenes.

Lo que significa el deseo de imágenes es que, cuando imaginamos las cosas, existimos. No puedo pertenecer a este mundo si no puedo decir que lo imagino de mi propia manera. Cuando un ciego dice "imagino" ello significa que él también tiene una representación interna de realidades externas. (Mayer,1999)

A partir de cada una de sus fotografías realizamos diferentes lecturas que nos permitían profundizar en su significado generando un vocabulario visual que serviría finalmente para crear sus propias imágenes.

La primera aproximación a la imagen la llamaremos lectura intuitiva. Le pedimos que comentara todos aquellos detalles que conociera o recordara de aquel momento fotografiado para ir teniendo una primera impresión de la información visual y los recuerdos que guardaba.

El siguiente paso consistía en realizar una lectura denotativa de la imagen detallando todos aquellos elementos presentes y situarlos en el formato de la fotografía. Realizamos una descripción previa tratando de entender los diferentes planos que abarcaba la imagen partiendo desde lo más lejano a lo más cercano y tener una idea clara de cómo se distribuyen de los elementos en la escena. Previamente fue necesario recordar que la fotografía es una imagen bidimensional formada por la superposición de diferentes planos que sierven para dar profundidad Seguidamente, se realizó un dibujo bajo indicaciones para trasladar visualmente la imagen que habíamos descrito. A nuestros ojos, ésta parecía ser la forma de demostrarnos que era capaz de visualizar mentalmente la fotografía. El dibujo se realizó sobre una superficie mullida, la cual le permitía realizar un trazo con el relieve suficiente para que quedara registrado tanto a los ojos como al tacto.

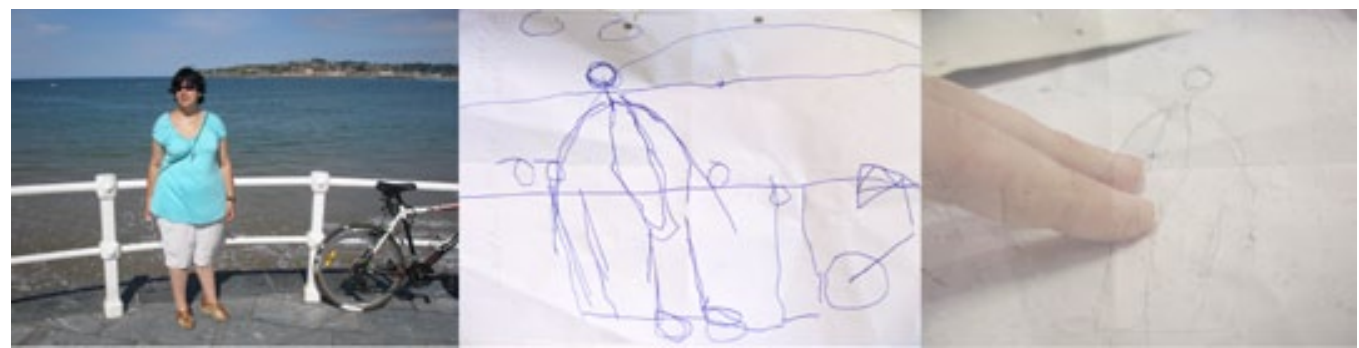

La siguiente lectura supone avanzar en el nivel de significación de la imagen para comentar otros aspectos no menos importantes que la fotografía puede evocar. La lectura connotativa describía la significación que puede tener la imagen para el espectador referiéndose a aspectos que no necesariamente son visibles a nuestros ojos. Barthes utiliza el término "el campo ciego" (1990, pp.105-111) cuando la fotografía nos arrastra fuera del marco de la propia imagen por una memoria o recuerdo que se hace presente y nos aleja del espacio físico y temporal de la propia imagen. El campo ciego configura un espacio invisible al que mentalmente nos trasladamos al mirar ese soporte visible que es la fotografía. En este caso, tratamos de que 
2nd International Conference Art, Illustration and Visual Culture in Infant and Primary Education
Figura 2. Composición fotográfica que muestra la escritura en sistema Braille de la frase "Una foto para mirar sin ojos". (5 de marzo de 2012). Facultad de Educación y Trabajo Social de la Universidad de Valladolid, España. Fuente: Noemí Peña.

\subsection{Interpretación creativa a partir de la fotografía.}

esta lectura ampliara su significado narrando lo visible e invisible presente en la fotografía y situarnos mentalmente en el espacio y tiempo en que fue tomada la fotografía. Esta es una de las partes que más posibilidades daba para generar nuevos discursos sobre la imagen ya que nos encontramos con reflexiones sorprendentes, detalles que pasan desapercibidos a nuestros ojos y que, sin embargo, tenían su presencia. Estas imágenes esbozaban otro tipo de imágenes que sin duda eran invisibles a nuestros ojos.

Merece la pena destacar una obra realizada con algunas fotografías impresas sobre las que se escribieron en braille algunas frases que narraban una breve interpretación. Entre las fotografías trabajadas destaca una de ellas, la cual corresponde con el retrato de una amiga ciega con la que se intercambiaron sus retratos fotográficos. Ambas no pueden verse, sin embargo, la fotografía es una forma de poseer la presencia ajena y explica esa necesidad visual que también tienen las personas ciegas. Este deseo de posesión también es descrito por Bavcar "No es ninguna casualidad que la primera foto que tomó en su vida, con un aparato rusos, una Zorki 6, fuera la de una niña que le gustaba en el colegio, una niña que amaba y a la que no podía, obviamente ver.(Replinger, 2004:91).

Lo curioso de estos retratos intercambiados es el hecho de compartir imágenes por la significación que aporta la posesión de la fotografía del otro aunque ésta no pueda contemplarse. La fotografía se comparte y se entiende del mismo modo que las personas que vemos. La estudiante escribió en braille sobre la imagen "Una foto para mirar sin ojos" tratando de que la palabra ojos coincidiera con los ojos de su amiga retratada.

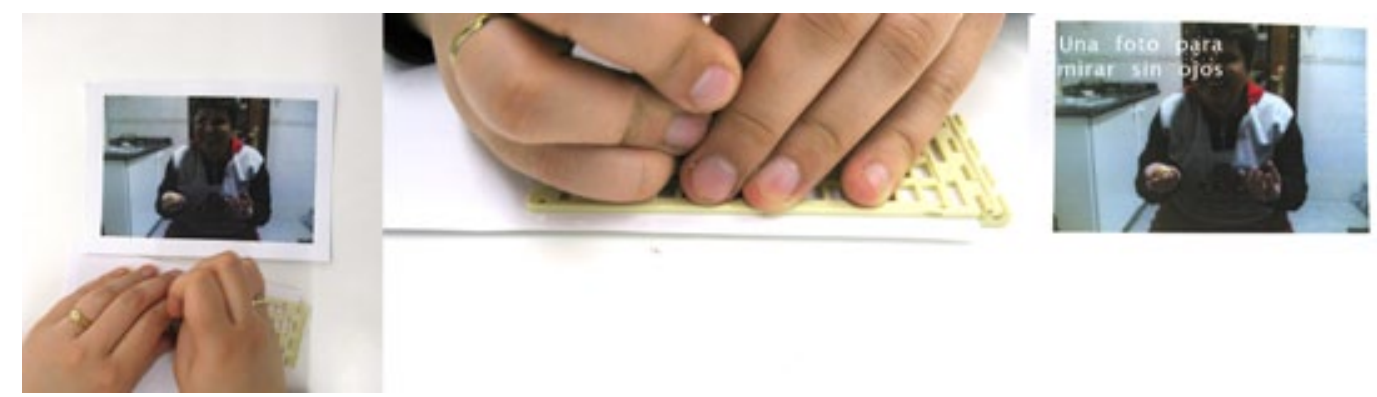

Aprovechando la riqueza narrativa de las anteriores descripciones planteamos realizar su propia creación a modo de interpretación personal sobre la imagen previamente leída. Para materializarlo pensamos en el collage como la mejor forma de combinar diferentes materiales y texturas que sugiriesen sensaciones vinculadas con la imagen. La interpretación creativa a partir de la fotografía, suponía relacionar aspectos trabajados en las diversas lecturas empleando un vocabulario visual conocido y generar sus propias imágenes creativas.
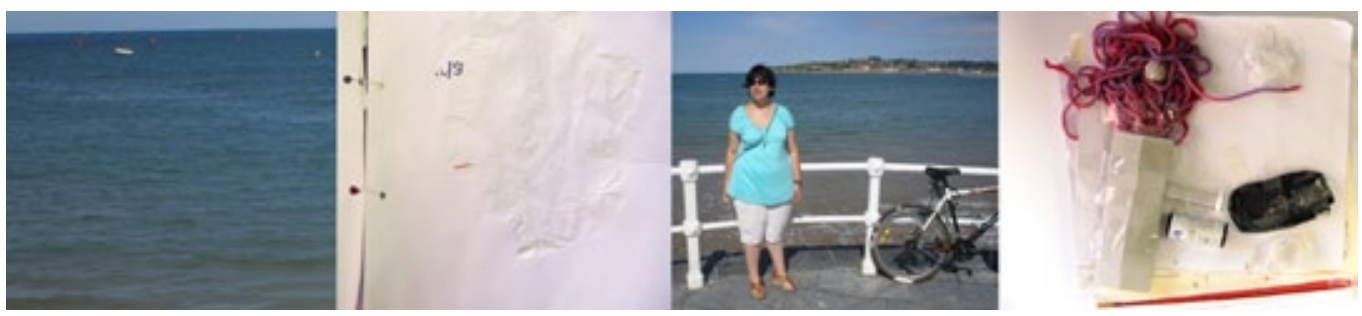

Cada uno de estos collages trataba de identificar aspectos perceptibles pero no necesariamente referidos a lo visual. Por ejemplo, la textura del plástico en el papel simulando el tacto del agua en el mar y la representación táctil de la fotografía a través de materiales que despertarán esas mismas sensaciones configurando imágenes originales que van más allá de nuestra propia mirada. Estas creaciones resultaron ser un excelente ejemplo de cómo las personas ciegas son capaces de crear imágenes originales, no sólo representándolas mentalmente, sino de materializarlas plásticamente aportando sentido a la creación artística y visual. 
2nd International Conference Art, Illustration and Visual Culture in Infant and Primary Education
Congresso Internaciona de Arte, llustração e Cultura Visual na Educação Infantil e Primária

Durante los diversos encuentros hemos podido observar como a medida que avanzábamos en el desarrollo de la asignatura, la actitud y la motivación para generar nuevas imágenes ha ido aumentando y es que de algún modo, hemos despertado esa necesidad visual de crear mensajes a través de un lenguaje visual, algo que están desacostumbradas gran parte de las personas ciegas.

\begin{abstract}
Aún aquellos que no pueden ver tienen dentro de ellos mismos lo que podríamos llamar necesidad visual. Una persona en una habitación oscura necesita ver la luz y la busca a toda costa. Ésta es la misma necesidad que expreso cuando saco una foto. Los ciegos suspiran por la luz como
\end{abstract} un niño en un tren mientras viaja por el túnel. (Meyer, 1999)

Estas imágenes creadas por una persona invidente ponen de manifiesto que las diversas lecturas son enriquecedoras para potenciar la percepción enriqueciendo el imaginario visual y ofreciendo la posibilidad de pensar en otras nuevas imágenes que sintetizan lo más significativo para el que las mira y que construyen la memoria visual de fotografías personales.

\title{
Conclusión
}

El trabajo con imágenes nos ha permitido aproximarnos al entorno visual de una estudiante ciega y comprender la importancia de potenciar todo ese proceso perceptivo desde edades tempranas, sin olvidarnos de dotar al individuo de recursos y estrategias para saber comunicarse a través de diversos códigos. En esta experiencia hemos podido comprobar como la persona invidente no sólo es capaz de acceder al mundo de las imágenes y comprender su significado, sino que es posible construir sus propias imágenes conectando con su imaginación y memoria. La educación artística tiene un papel clave en la formación de las personas invidentes y que debe trabajarse por personas especialistas para su adecuado desarrollo.

La estudiante ciega como futura maestra de educación primaria debe comprender como la formación artística debe ser parte de la educación integral del alumnado y concienciarse de que un mundo con imágenes forma parte del entorno de todos los que miran y de los que poseen ese deseo de imágenes aunque no puedan ver.

\section{Referencias bibliográficas}

Ewald, W. (2001). I wanna take me a picture. Teaching photography and writing to children.Boston: Beacon Press.

Gratacós, R. (2006). Otras miradas. Arte y ciegos: tan lejos, tan cerca. Barcelona: Octaedro.

Mayer, B.(1999). Evgen Bavcar: el deseo de imagen. Luna Córnea, nº17.

Menchén, F. (1998) Descubrir la creatividad. Desaprender para volver a aprender. Madrid: Pirámide.

Peña, N. (2011) "Entrevista a Wendy Ewald ¿Cómo desarrollar propuestas colaborativas utilizando la fotografía?"Revista Pulso, n. 34.pp. 211-223.

Replinger, M.(2004) "Evgen Bavcar: mecanismos de simulación y el concepto de índex fotográfico". Caminos de la Semiótica en la última década del S. XX. Valladolid: U.V.A 